\title{
Accelerating Biocatalytic Hydrogenations using the H-Cube Flow Reactor
}

\author{
Barnabas Poznansky, ${ }^{\ddagger}$ Lisa A. Thompson, ${ }^{\ddagger}$ Holly A. Reeve, ${ }^{*}$ and Kylie A. Vincent* \\ Department of Chemistry, University of Oxford, Inorganic Chemistry Laboratory, South Parks Road, \\ Oxford, OX1 3QR, UK
}

KEYWORDS Biocatalysis, Continuous flow, Hydrogenation, H-Cube, Cofactor recycling.

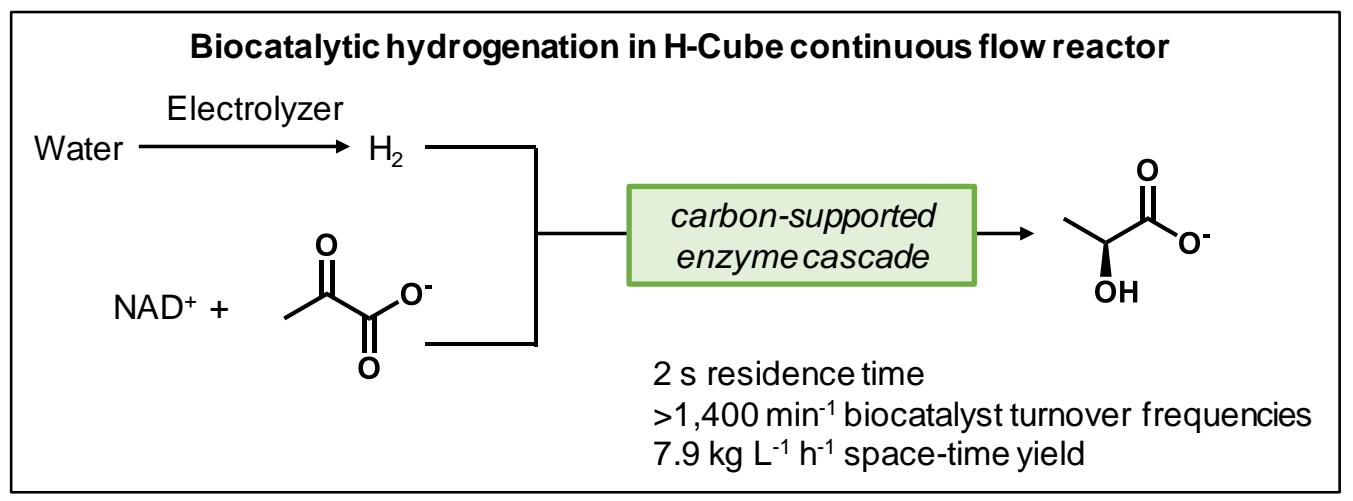

ABSTRACT: Translation of redox biocatalysis into a commercial H-Cube hydrogenation flow reactor was achieved using immobilized enzyme systems for biocatalytic hydrogenations. Carbon-supported enzymes for $\mathrm{H}_{2}$-driven $\mathrm{NADH}$ recycling and $\mathrm{NADH}$-dependent $\mathrm{C}=\mathrm{O}$ reductions were handled comparably to supported metal catalysts. High activity at room temperature with 2 bar $\mathrm{H}_{2}$ was attained, highlighting that biocatalytic strategies enable implementation of hydrogenation reactions under mild conditions. High conversions were achieved in short residence times $(<2 \mathrm{~s})$, with high biocatalyst turnover frequencies $\left(1,420 \mathrm{~min}^{-1}\right)$ and space-time yields $\left(7.9 \mathrm{~kg} \mathrm{~L}^{-1}\right.$ $\left.\mathrm{h}^{-1}\right)$. These results represent the first example of direct biocatalytic hydrogenation in a commercial flow reactor. 
As sustainability increases in importance in the chemical and pharmaceutical industries, new technologies that lower energy demands, use renewable resources and aid productivity are critical. Flow packed bed reactors are one such technology. The small reactor footprint allows improved control over temperature and pressure leading to safer reactions, and can have further benefits for productivity, clean-up costs associated with catalyst recovery and possibilities for multistep synthesis without a need for purification of the intermediates. In the area of hydrogenation chemistry, supported precious metal catalysts driven by clean $\mathrm{H}_{2}$ gas, Figure $1(\mathrm{a})$, are increasingly implemented in continuous flow packed bed reactors, which improves $\mathrm{H}_{2}$ availability relative to reaction volume and overcomes the need to separate metal catalyst from the reaction products. Biocatalysis relies on renewable catalysts, operates under mild reaction conditions and provides exquisite control over chemical selectivity, Figure 1(b), however, the reliance on reductants such as glucose or formate leads to high waste production, and complicates translation into flow reactors.

(a) Catalytic hydrogenation: $\mathrm{H}_{2}$-driven metal catalysis

(b) Biocatalysis: Glucose driven biological catalysts
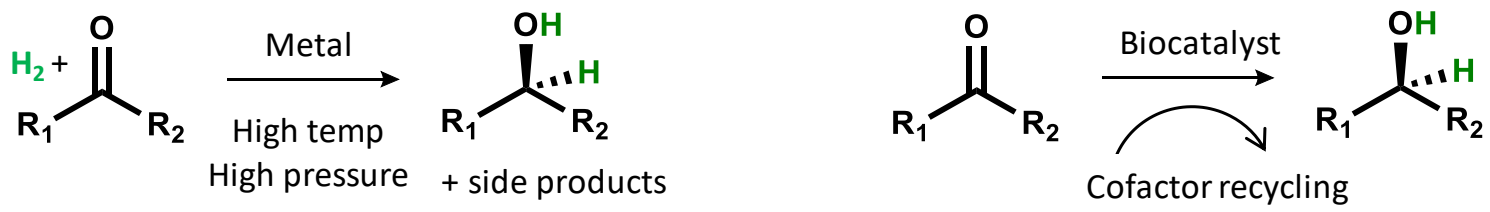

Waste product

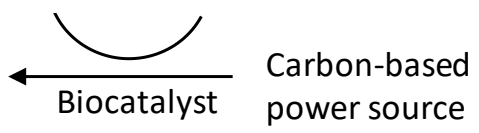

e.g. Glucose

(c) Biocatalytic hydrogenation: replacing metals and decarbonising biocatalysis
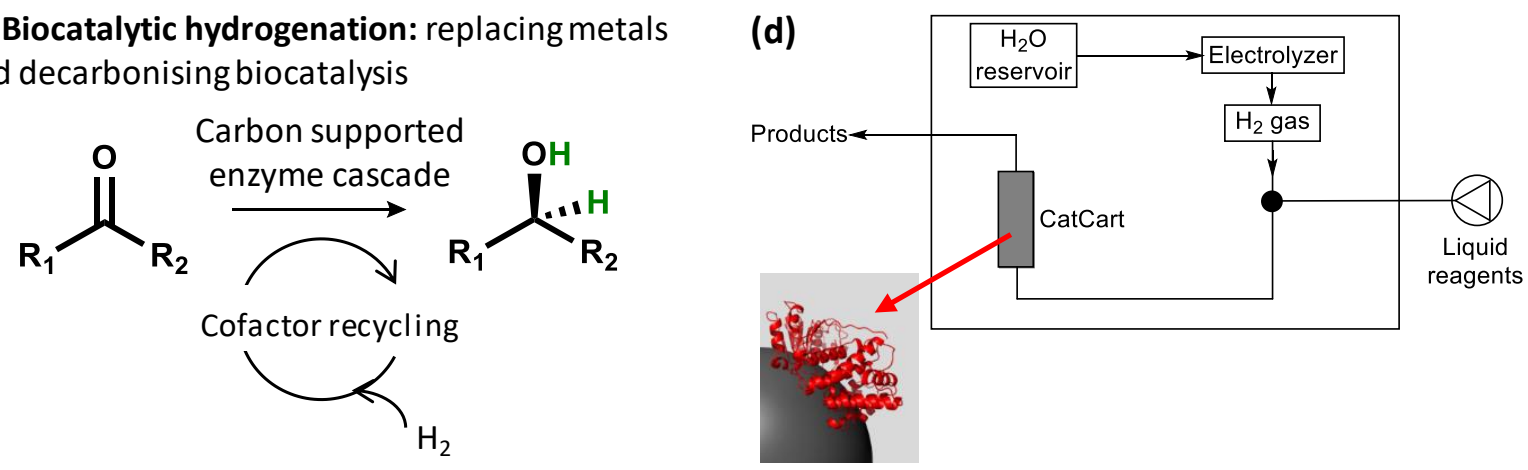

Figure 1. Comparison of industry standard methods for $\mathrm{C}=\mathrm{X}$ bond reductions with biocatalytic hydrogenation strategies investigated here. (a) Metal-catalyzed hydrogenation affords atom efficient reactions. (b) Renewable biological catalysts offer near perfect chemical selectivity under mild reactions conditions. (c) Biocatalytic hydrogenation can be achieved using $\mathrm{H}_{2}$-driven cofactor recycling. (d) Schematic of $\mathrm{H}$-Cube reactor, showing built-in electrolyzer for in situ $\mathrm{H}_{2}$ gas generation, with CatCart ${ }^{\mathrm{TM}}$ containing carbon-supported biocatalyst cascades.

Demonstrations of $\mathrm{H}_{2}$-driven cofactor recycling, extended to drive biocatalytic $\mathrm{C}=\mathrm{X}$ bond reductions, aim to bridge between the atom economy of catalytic hydrogenation and the precision of biocatalysis, Figure 1 (c). Such $\mathrm{H}_{2^{-}}$ powered biotransformations have been demonstrated in batch reactions, and more recently have been extended to re-circulating flow reactors, ${ }^{17}$ and into continuous flow. ${ }^{3,16}$ In our previous work, biocatalytic hydrogenations were achieved using in house flow columns, but we were not able to achieve the control of $\mathrm{H}_{2}$ introduction that commercial reactors can provide. Here, we sought to demonstrate biocatalytic hydrogenation in an industry standard flow reactor, the H-Cube, Figure $1(\mathrm{~d})$, for generation of reduced cofactor, NADH, and for NADH supply to $\mathrm{NADH}$-dependent enzymes for $\mathrm{C}=\mathrm{O}$ reductions. 
To study the immobilized biocatalyst in the $\mathrm{H}$-Cube reactor, the carbon supported enzyme system was packed into CatCarts ${ }^{\mathrm{TM}}$, that are specially designed for use with the $\mathrm{H}$-Cube reactor. The sealed cartridges were then stored at $4{ }^{\circ} \mathrm{C}$ for $1 \mathrm{~h}$, to allow for enzyme adsorption to take place. The enzyme-loaded cartridges were then installed in the $\mathrm{H}$-Cube reactor for the $\mathrm{H}_{2}$-powered reactions. Initially, conversion of $\mathrm{NAD}^{+} \mathbf{1}$ to $\mathrm{NADH} \mathbf{2}$ (Scheme 1 ) was trialled.
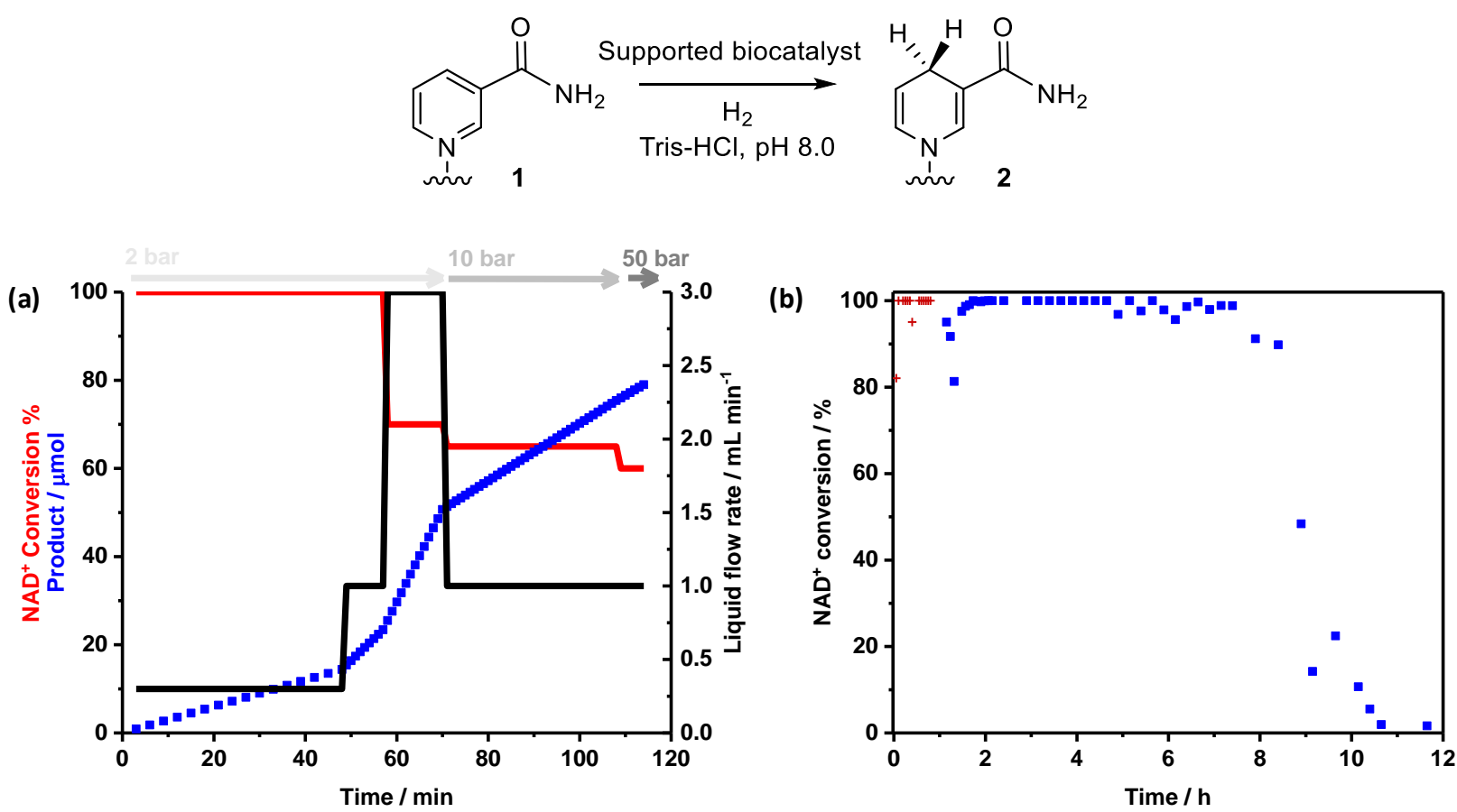

Figure 2. $\mathrm{H}_{2}$-powered conversion of $\mathrm{NAD}^{+}(1)$ to $\mathrm{NADH}(2)$ in the biocatalytic cartridge. (a) Conversion of $\mathrm{NAD}^{+}(1 \mathrm{mM})$ to $\mathrm{NADH}$ (red line, left axis) using the $\mathrm{H}$-Cube reactor, under different liquid flow rates (black line, right axis) and pressures (top axis). Cumulative amount of product formed (blue squares, left axis) during the reaction. (b) Conversion of $3 \mathrm{mM}$ (red cross) and $5 \mathrm{mM}$ (blue square) $\mathrm{NAD}^{+}$using the $\mathrm{H}$-Cube reactor. Reaction conditions: $50 \mathrm{mM} \mathrm{Tris-} \mathrm{HCl}$ buffer, $\mathrm{pH} 8.0,25^{\circ} \mathrm{C}$, tRes $=1.7 \mathrm{~s}$, liquid flow rate $=0.1 \mathrm{~mL} \mathrm{~min}^{-1}$, gas flow rate $=\sim 7 \mathrm{~mL} \mathrm{~min}^{-1}$, reactor volume $=0.2 \mathrm{~mL}$.

Reaction solution containing $\mathrm{NAD}^{+}(1 \mathrm{mM})$ in Tris-HCl buffer $(50 \mathrm{mM}, \mathrm{pH}$ 8.0) was pumped into the $\mathrm{H}$-Cube reactor system at a range of flow rates $\left(0.3,1\right.$ or $\left.3 \mathrm{~mL} \mathrm{~min}^{-1}\right)$, where it was combined with the $\mathrm{H}_{2}$ from the built-in electrolyzer (approx. $12 \mathrm{~mL} \mathrm{~min}^{-1}$ ). The system pressure was set to 2, 10 or 50 bar. These parameters were tested in sequence, using the same biocatalytic cartridge $(0.2 \mathrm{~mL}$ reactor volume) and the results are shown in Figure 2(a).

Quantitative conversion to NADH was achieved for flow rates of 0.3 and $1 \mathrm{~mL} \mathrm{~min}^{-1}$ at 2 bar. At $3 \mathrm{~mL} \mathrm{~min}^{-1}$ the highest biocatalyst turnover frequency (TOF) of $223 \mathrm{~min}^{-1}$ was achieved (70\% conversion), likely due to improved substrate availability. Increasing the pressure to 10 bar showed lower conversion (65\%) than at 2 bar for $1 \mathrm{~mL}$ $\mathrm{min}^{-1}$, however further increasing the system pressure to 50 bar had little effect on the conversion (60\%) compared to 10 bar. This demonstrated the stability of the biocatalytic cartridge at elevated pressure and, although the enzyme system does not require high pressure for operation, it shows the potential for use in multistep continuous processes where higher pressures may be required for other reaction steps.

We next increased the substrate throughput by performing experiments using higher concentrations of $\mathrm{NAD}^{+}$over a longer period of time. A single biocatalytic cartridge was tested for both 3 and $5 \mathrm{mM} \mathrm{NAD}^{+}$, using a liquid flow rate of $0.1 \mathrm{~mL} \mathrm{~min}^{-1}$ and $\mathrm{H}_{2}$ flow rate of $7 \mathrm{~mL} \mathrm{~min}^{-1}$ (residence time, tRes $=1.7 \mathrm{~s}$ ). At $3 \mathrm{mM} \mathrm{NAD}^{+}$, full conversion to 
NADH was maintained for $1.1 \mathrm{~h}$ (Figure 2(b), red cross), after which the concentration of NAD ${ }^{+}$was increased to 5 $\mathrm{mM}$ (Figure 2(b), blue square). High conversion was maintained (>98\%) for a further $6.3 \mathrm{~h}$, before the conversion decreased over the subsequent $4 \mathrm{~h}$. Under these conditions, the system operated at a space-time yield (STY) of 7.9 $\mathrm{kg}_{\mathrm{NADH}} \mathrm{L}^{-1} \mathrm{~h}^{-1}$ (0.2 $\mathrm{mL}$ reactor volume) and an $\mathrm{E}$ factor of 0.9 .

The stability of the system was shown over a total of $11.5 \mathrm{~h}$ (24,300 reactor volumes), producing $173 \mathrm{mg}$ of $\mathrm{NADH}$, and providing a catalyst total turnover number (TTN, moles of product per mole of enzyme) of 26,000. The high conversion at short tRes, with high catalyst TOF, demonstrate the potential for fast regeneration of cofactor to supply NADH-dependent biocatalysis.

A biocatalyst cartridge combining enzymes for $\mathrm{H}_{2}$-driven cofactor recycling coupled to ketone reduction of pyruvate (3) to lactate (4) was prepared, and installed into the $\mathrm{H}$-Cube (Figure 3 ).
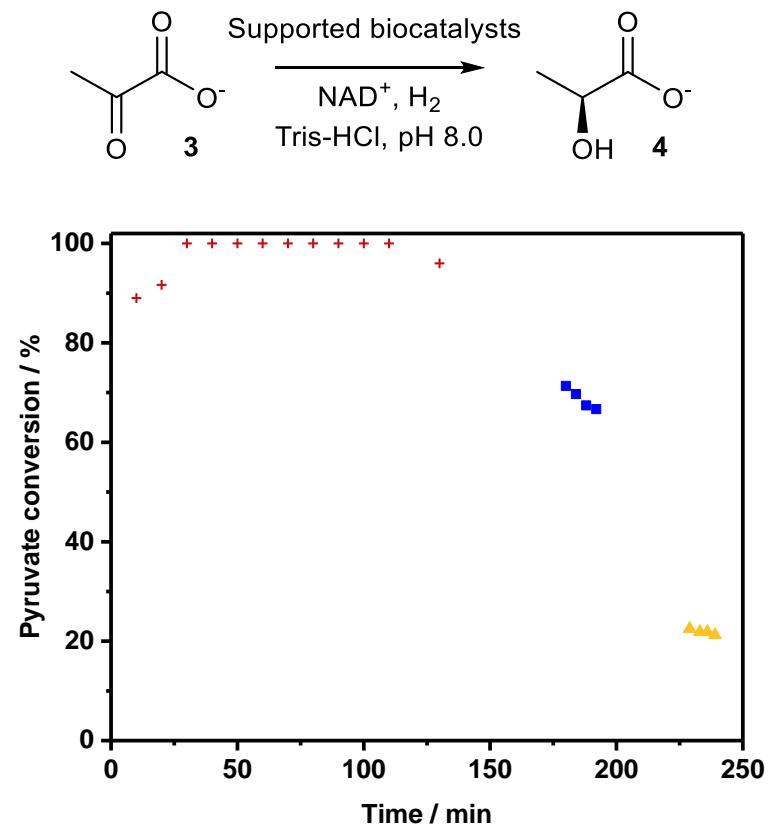

Figure 3. $\mathrm{H}_{2}$-powered conversion of pyruvate (3) to lactate (4) in the combined biocatalyst cartridge. Conversion of 3 to 4 , under different liquid flow rates, in the H-Cube reactor. Red cross $=0.1 \mathrm{~mL} \mathrm{~min}{ }^{-1}$, blue square $=0.5 \mathrm{~mL} \mathrm{~min}^{-1}$, yellow triangle

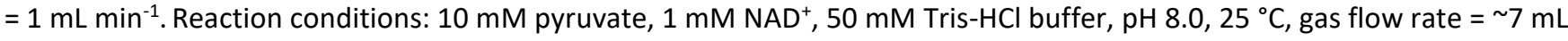
$\min ^{-1}$, reactor volume $=0.2 \mathrm{~mL}$.

The $\mathrm{H}$-Cube reactor was set-up with a single liquid feed containing sodium pyruvate $(10 \mathrm{mM})$ and $\mathrm{NAD}^{+}(1 \mathrm{mM})$ in Tris- $\mathrm{HCl}$ buffer $(50 \mathrm{mM}, \mathrm{pH} 8.0)$. The liquid flow rate was set to $0.1,0.5$ or $1 \mathrm{~mL} \mathrm{~min}^{-1}$, equating to tRes of $1.7 \mathrm{~s}, 1.6$ $\mathrm{s}$ or $1.5 \mathrm{~s}$, when combined with a $\mathrm{H}_{2}$ flow rate of $7 \mathrm{~mL} \mathrm{~min}^{-1}$. For each set of conditions the reactor was allowed to reach steady-state and then multiple fractions were collected for analysis by ${ }^{1} \mathrm{H}$ NMR spectroscopy.

The results in Figure 3 show that the conversion of pyruvate to lactate reached a steady-state conversion of $>96 \%$ at $0.1 \mathrm{~mL} \mathrm{~min}^{-1}$ liquid flow rate (1.7 s tRes), which was maintained for $100 \mathrm{~min}$ (3,529 reactor volumes). This corresponded to a STY of $2.5 \mathrm{~kg}_{\text {lactate }} \mathrm{L}^{-1} \mathrm{~h}^{-1}$ and an $\mathrm{E}$ factor of 5.4. The conversions achieved at $0.5 \mathrm{~mL} \mathrm{~min}^{-1}$ and 1

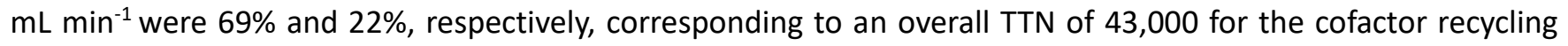
system across the whole experiment.

An additional experiment was carried out using more forcing reaction conditions with the aim of achieving higher enzyme turnover numbers in the combined biocatalyst cartridges. The sodium pyruvate concentration was increased to $20 \mathrm{mM}$ and a higher liquid flow rate of $0.5 \mathrm{~mL} \mathrm{~min}{ }^{-1}$ was used, with $1 \mathrm{mM} \mathrm{NAD}^{+}$. Over $210 \mathrm{~min}$, a TTN 
of 98,000 for the cofactor recycling catalyst with a TOF of $1,420 \mathrm{~min}^{-1}\left(85,200 \mathrm{~h}^{-1}\right)$ was reached, which is at the top end of typical rates achieved for the metal-catalyzed transfer hydrogenation of ketones $\left(10^{2}-10^{5} \mathrm{~h}^{-1}\right){ }^{19}$

In order to demonstrate the feasibility of active pharmaceutical ingredient (API) synthesis via biocatalytic hydrogenation in the $\mathrm{H}$-Cube flow reactor a biocatalyst column was prepared for the conversion of 3quinuclidinone (5) to (R)-3-quinuclidinol (6), a component of a number of APIs (Scheme 3).

Scheme 1. H2-powered conversion of 3-quinuclidinone (5) to 3-quinuclidinol (6) in the combined biocatalyst cartridge.

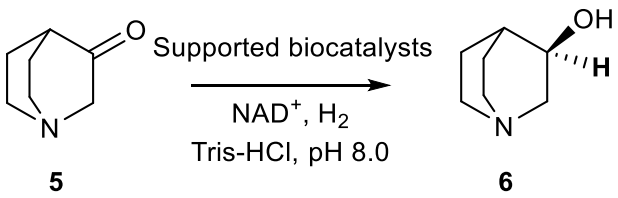

A reaction solution of $5(10 \mathrm{mM})$ and $\mathrm{NAD}^{+}(1 \mathrm{mM})$ was pumped through a CatCart ${ }^{\mathrm{TM}}$ pre-loaded with the enzymemodified carbon at a liquid flow rate of $0.1 \mathrm{~mL} \mathrm{~min}^{-1}(1.7 \mathrm{~s}$ tRes). The system reached a steady-state conversion of $60 \%$, corresponding to a STY of $2.1 \mathrm{~kg} \mathrm{~L}^{-1} \mathrm{~h}^{-1}$ and an $\mathrm{E}$ factor of 6.8 , demonstrating the use of this biocatalytic $\mathrm{H}-$ cube system for clean, efficient synthesis of pharmaceutical precursors.

\section{Conclusion}

We have demonstrated carbon-supported biocatalytic hydrogenations in a commercial $\mathrm{H}$-Cube flow reactor achieving full conversions in very short tRes (seconds). The $\mathrm{H}_{2}$ gas is provided in situ by electrolysis, opening up the possibility of using renewable electricity to drive $100 \%$ atom efficient biocatalytic $\mathrm{C}=\mathrm{X}$ reductions. This system has the potential to be extended to provide rapid $\mathrm{H}_{2}$-powered cofactor regeneration for a wide range of $\mathrm{NADH}$ dependent enzymes. To the best of our knowledge, this is the first example of $\mathrm{H}_{2}$-powered biocatalysis carried out in the $\mathrm{H}$-Cube reactor using custom-prepared catalyst cartridges, which gives comparable catalyst TOF to supported metal catalyst columns but under mild reaction conditions. The straightforward transfer of carbonsupported biocatalysts into a commercial flow cartridge highlights how this biocatalytic route could be slotted into existing hydrogenation flow reactor infrastructure, simplifying the adoption of NADH-dependent biocatalytic steps for asymmetric synthesis.

\section{AUTHOR INFORMATION}

\section{Corresponding Author}

*Email:

kylie.vincent@chem.ox.ac.uk, holly.reeve@chem.ox.ac.uk

\section{Author Contributions}

B.P., L.A.T. and H.A.R. performed experiments; B.P., L.A.T. and H.A.R. analyzed data. The manuscript was written through contributions of all authors. All authors have given approval to the final version of the manuscript. ¥These authors contributed equally.

\section{Funding Sources}

L.A.T., H.A.R. and K.A.V. are supported by Engineering and Physical Sciences Research Council (EPSRC) IB Catalyst award EP/N013514/1. B.P. is supported by iCASE funding from the Biotechnology and Biological Sciences Research Council (BBSRC) [Grant number BB/M011224/1], with support from Dr. Reddy's Laboratories. 


\section{ACKNOWLEDGMENT}

The authors would like to thank ThalesNano for access to an H-Cube Pro demonstration reactor and Dr Matthew Bycroft (Dr. Reddy's) for useful discussions and project support, and Dr Miguel Ramirez for preparation of enzyme samples.

\section{ABBREVIATIONS}

API, active pharmaceutical ingredient; STY, space-time yield; TOF, turnover frequency; tRes, residence time; TTN, total turnover number.

\section{REFERENCES}

1 J. S. Carey, D. Laffan, C. Thomson and M. T. Williams, Org. Biomol. Chem., 2006, 4, 2337-2347.

2 H. A. Reeve, L. Lauterbach, O. Lenz and K. A. Vincent, ChemCatChem, 2015, 7, 3480-3487.

3 C. Zor, H. A. Reeve, J. Quinson, L. A. Thompson, T. H. Lonsdale, F. Dillon, N. Grobert and K. A. Vincent, Chem. Commun., 2017, 53, 9839-9841.

4 L. A. Thompson, J. S. Rowbotham, H. A. Reeve, C. Zor, N. Grobert and K. A. Vincent, in Methods in Enzymology, 630th edn., 2020, pp. 303-325.

5 A. R. Bogdan and A. W. Dombrowski, J. Med. Chem., 2019, 62, 6422-6468.

6 C. Badman, C. L. Cooney, A. Florence, K. Konstantinov, M. Krumme, S. Mascia, M. Nasr and B. L. Trout, J. Pharm. Sci., 2019, 108, 3521-3523.

7 M. Baumann, T. S. Moody, M. Smyth and S. Wharry, Org. Process Res. Dev., , DOI:10.1021/acs.oprd.9b00524.

8 J. Britton, S. Majumdar and G. A. Weiss, Chem. Soc. Rev., 2018, 47, 5891-5918.

9 L. Tamborini, P. Fernandes, F. Paradisi and F. Molinari, Trends Biotechnol., 2018, 36, 73-88.

10 M. P. Thompson, I. Peñafiel, S. C. Cosgrove and N. J. Turner, Org. Process Res. Dev., 2019, 23, 9-18.

11 M. Irfan, T. N. Glasnov and C. O. Kappe, ChemSusChem, 2011, 4, 300-316.

12 P. J. Cossar, L. Hizartzidis, M. I. Simone, A. McCluskey and C. P. Gordon, Org. Biomol. Chem., 2015, 13, 7119-7130.

13 C. C. Russell, J. R. Baker, P. J. Cossar and A. McCluskey, in New Advances in Hydrogenation Processes Fundamentals and Applications, InTech, 2017.

14 R. V. Jones, L. Godorhazy, N. Varga, D. Szalay, L. Urge and F. Darvas, J. Comb. Chem., 2006, 8, 110-116.

15 H-Cube ${ }^{\circledast}$ Pro - ThalesNano, https://thalesnano.com/products-and-services/h-cube-pro/, (accessed 30 January 2020).

16 L. A. Thompson, J. S. Rowbotham, J. H. Nicholson, M. A. Ramirez, C. Zor, H. A. Reeve, N. Grobert and K. A. Vincent, ChemCatChem, in press, DOI:10.1002/cctc.202000161.

17 A. Al-Shameri, M.-C. Petrich, K. junge Puring, U.-P. Apfel, B. Nestl and L. Lauterbach, Angew. Chemie Int. Ed., 2020, 59, 10929-10933.

18 B. Poznansky, L. A. Thompson, S. A. Warren, H. A. Reeve and K. A. Vincent, Org. Process Res. Dev., in press, DOI:10.1021/acs.oprd.9b00410.

19 B. Štefane and F. Požgan, Top. Curr. Chem., 2016, 374, 18. 